\title{
Managing Urban Landscape Towards the Sustainable City: a Case Study from Northern Greece
}

\author{
Paraskevi - Kali Sofianou ${ }^{1, a}$ \\ ${ }^{1}$ Aristotle University of Thessaloniki, School of Civil Engineering, Division of Transportation, \\ Construction Management and Regional Planning, Thessaloniki, Greece \\ asofianou@civil.auth.gr
}

\begin{abstract}
Keywords: Sustainable Development, Sustainable City, Land Use Management, Urban Environmental Management, Socio-Economical Growth.
\end{abstract}

\begin{abstract}
One of the areas of human activity which exerts severe pressure on the environment is the management of urban landscape. Many of the modern Greek cities have experienced intense urbanization and expanding without the appropriate means to support them. The continuous expansion of built environment, the degradation of living conditions due to pollution etc., are some of the factors that threaten the contemporary urban environment and hinder progress towards the sustainable city.

The aim of this paper is to map the problems and opportunities that a city of Northern Greece, Komotini, with rich natural, historical and multicultural backgrounds, presents. An attempt is made to evaluate the city's current situation as well as to propose some main targeted development policies for ameliorating the urban environment of the city. The ultimate goal is to reorganize the basic factors that compose the function of this urban center, following the principles of sustainable development.
\end{abstract}

\section{Introduction}

Modern societies must confront a number of changes that concern human settlements in general, and urban conservation in particular. One of the areas of sustainable development, with direct influences on humans and on natural environment, is urban planning and operation of the built environment. Moving away from the previous model of economic growth towards sustainable development, poses new bases in the structure of socio-economical and political values. Komotini as a case study is a large urban center of Northern Greece, seat of the administrative region of East Macedonia and Thrace with various responsibilities and hub between Greece, Turkey and Bulgaria.

The lack of planning, led to deconstruction of the adopted economic and technocratic system.

\section{Historical and urban development of Komotini}

A first residential trace appeared in the $14^{\text {th }}$ century, as evidenced by the Byzantine fortress. It was built near ancient Via Egnatia (West - East connection) and the river Mpoukloutza, vital for the city's life. Thus, a first urban organization began to appear, with the space in the fort as the gravity center. During Turkish domination, the Christian neighborhood remained within the walls, while the Muslims settled outside the fort and around the river. The city expanded northeast based on oriental spatial patterns, with via Egnatia and the river as reference axis.

In 1920 the city was liberated. In 1933, due to rapid population growth, a spatial plan following the existing labyrinthine routes was drafted. In the 1950's began the city's modernization, with the diversion of the river, the establishment of Democritus University of Thrace (the administration of which is headquartered in Komotini), the Urban Planning Zone and the Urban Development Plan. 


\section{Spatial and urban structure}

\section{General framework of urban planning and land use that defined modern Greek cities.}

Before the industrial revolution, urban centers were few and not densely built. People lived in rural settlements and worked in the primary sector. The phenomenon of vast urbanization increased during the second half of the previous century, with internal migrating from rural areas to the urban centers resulting in an urbanization of the rural land [1], especially after World War II and due to the socio-economical collapse and lack of opportunities. Cities started to expand beyond their boundaries in informal settlements. The absence of political initiative for management of urban space led to urban sprawl.

Suddenly, urban centers became recipients of a large number of residents. The lack of planning policy and the necessary legislative framework, led to phenomena such as land fragmentation, absence of land use planning, imposition of built environment at the expense of communal spaces, urban sprawl, crowding and mix of uses, environmental degradation etc. Komotini confronts many of the problems above, as it has accepted a large number of immigrants, mainly after the Asia Minor Catastrophe (1922). Since then, vigorous reconstruction and overlapping of free space appeared, that combined with other factors, determined the city's form up to the present day.

Specificities of Komotini's city plan. Komotini is a major urban center with many contrasts. History center is characterized by high-density and labyrinthine narrow streets and blocks. Residents must cope with limited urban open space, a measurable urban heat island effect, insufficient conditions of sunshine and natural ventilation and high concentrations of traffic pollution that fail to disperse from the numerous street canyons. Traffic congestion is very common, as well as lack of parking spaces, especially during peak hours. There is a great building stock underused, crowding and mix of uses, related to recreation, organized commerce and services.

South of downtown are located the refugee districts, the first example of Ippodamian system plan in the city, with small rectangular squares, dense housing and small public spaces. The massive influx of population arose the need for organized planning (until the 1920's the city followed oriental patterns with no town plan), and thus introduced new terms of layout. Main use is housing.

On the contrary, at north side, are located the Muslim neighborhoods with an introverted image, with main land use the residence and neighborhood commerce. Labyrinthine blocks and very narrow roads that often prohibit vehicle passage, low houses with tall concrete walls as the border between private and public space and lack of common spaces are the main characteristics of these regions. These areas should be treated in a particular way, due to the specificities they display.

The area that stands out is the Urban Control Zone (designed by important construction firms), on the upper west suburbs, near the campus. Based on the Ippodamian system, it has common and open-air spaces in leading role, low dense housing and innovative infrastructure towards bioclimatic architecture. Housing is the main use with education, recreation and commerce following.

Allocation of central uses. A large proportion of Komotini's population is occupied on the services sector because of the increased demand for services. Central functions are widespread, due to lack of strategic urban plan during the past decades and they are concentrated basically in the center or along the city's main streets. Consequently, the center zone of functions and activities cannot be easily distinguished. On the east side are located functions relevant to the primary and secondary economic sectors. Northwest there is a large area of low-density building, where the new university campus is located. On the suburbs there is not a definite character of land use, whilst there are department stores, industrial uses, wholesaling and services.

Furthermore, the urban transport stations are located around the center. The railway station is on the northwest suburbs. The intercity bus station is nearby the center from the south, and as a result, many problems of traffic flow appear in this area. There is no direct connection between the stations or an adequate pedestrian network to them. What is to be emphasized is the relocation of the fire brigade, which is located on the north side of the central square since the early 1900's. As a result, the proper operation of the fire station is hampered, due to traffic jam especially during peak hours.

Masterplan of Komotini. During the decade 1971-'81, a rapid population growth and housing needs occurred in the city, so, the need of strategic spatial and urban planning became urgent. The 
first project of regional planning (1982-'84) concerning all Greek prefectures [2], attempted to organize land uses countrywide, but did not find any application and Komotini remained without masterplan.

Until recently there was no clear urban and regional plan, or an integrated plan about Komotini's expansions (especially about the informal settlements around the city) and land uses. In 1983, a project concerning the development and consistency of the city and the suburbs, began, however, the particularities and the contradictory structure of its districts, prevented the accomplishment of this task. In 2012 the elaboration of the new general Urban Development Plan of Komotini was completed. This plan prioritizes the creation of Urban Control Zone in every direction around the city, siting and zoning of industry and wholesale functions at its entrances, management of residential areas in conurbations and new development zones [3]. It is important that it includes the urban planning of the area around the city and predicts the housing of 53,960 inhabitants. (Fig.1)

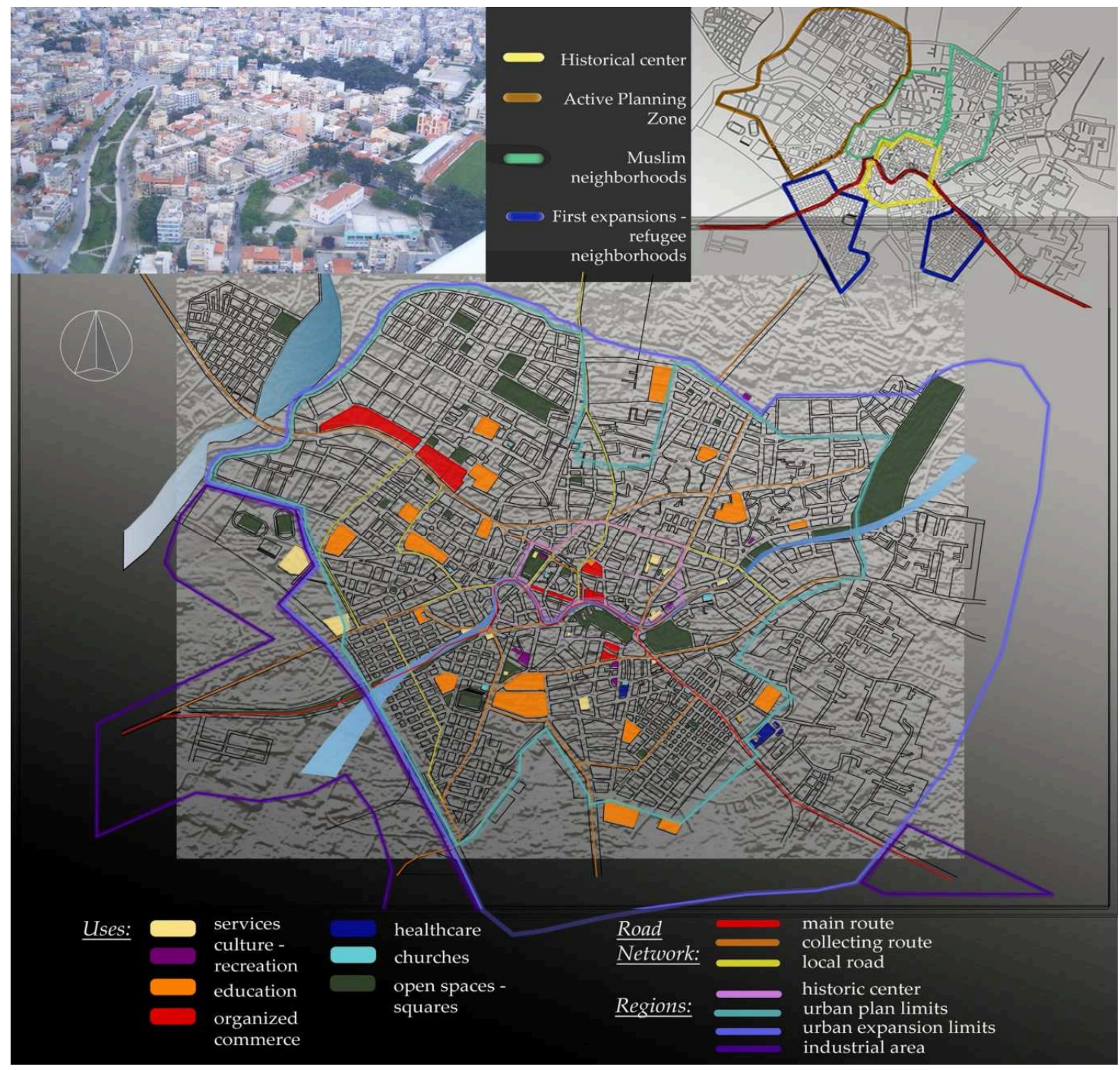

Fig.1: General city map, presenting the main regions and uses.

\section{Management of urban landscape of Komotini towards the sustainable city}

Main problems and factors that degrade the city structure. Space (especially urban space) is 'a good in insufficiency' [4], the proper management of which is the big challenge for modern societies. Komotini has to deal with major problems concerning form and function. There are still areas without main infrastructure and service networks (e.g. the settlements of Romani). Urban restrictions in specific areas (e.g. muslim neighborhoods), and the unevenness of the built environment, create strong contrasts between the city's districts. 
Decent housing stimulates both physical and economic improvement, and the resulting enhancements in turn stimulate new investment and new opportunities [5]. The absence of integrated housing development project led to informal settlements with high-rise buildings overlapping the blocks and degrading free spaces. Consequently, the ratio of green space per inhabitant in Komotini is low (urban green space in Komotini covers $1.95 \%$ of total urban space [6]). There are small parks and playgrounds with urban equipment of conventional materials. Given the location and the favorable climate, green space could increase, in order to improve Komotini's microclimate and quality of life.

The city center is hardly accessible in peak hours, because of lack of parking slots or a ring road to decongest it. The town is served by a local bus network, though it is difficult to maintain the timetable in the event of traffic congestion, road blockages or bad weather, and unpredictable problems resulting in delays and gaps in the timetable services scarcely can be dealt with. Parking violation is very common, because of few parking spaces and unreliable public transportation. Many cars park illegally on bus stops hindering easy and safe passenger boarding and alighting.

The absence of land use management resulted in the diffusion of uses in and out urban space and increased citizens' need to move by car. The accommodation of public services and facilities in the city is necessary. There are many buildings underused, most of them significant as examples of neoclassical or traditional folk architecture, the restoration of which could house municipal services, as constrained from expanding spatially by the shortage of buildable land. In addition, many of them belong to the municipality or the state, and this fact could reduce the leasehold property that today is needed for housing services. Furthermore, the revival of this architectural treasure would promote local heritage and culture, as well as local economy, through tourism development.

Perspectives for development based on the sustainable city's principles. The built environment involves complex socio-economic, environmental and political issues. Urban regeneration plan for livable built space is a global priority. Location of choices, areas of distinctive character, attractive pedestrian routes including new street types, enhanced city squares and green spaces should be required in the regeneration process as well as in sustainable urban living [7].

There are many ways to give some substance to the application of sustainability to cities. One of the theories of the previous decades presenting steps towards sustainability is the 'urban metabolism'. This concept conceived by Wolman, is fundamental to developing sustainable cities and communities [8]. The city is a system and urban spaces have functions and procedures similar to those of living organisms, with inputs, outputs and storage of energy, water, nutrients, materials and wastes. By looking at the city as a whole and by analyzing the pathways along which energy and materials including pollutants move, it is possible to begin to conceive of management systems and technologies which allow for the reintegration of natural processes, increasing efficiency of resource use, the recycling of wastes as valuable materials and the conservation of energy [9].

Today it is necessary to assess the state of Komotini and set sustainable long term goals and objectives. The turn to innovative planning, design using the area's abundant natural resources and sustainable policies that promote a "people-first" focus, is the main priority. The cities nowadays have to take full advantage of their scarce land. Land policies, appropriate legislature and monitoring are some of the means for functional and aesthetical urban environment.

Firstly, it is important to ameliorate the built environment. There are many ways to reduce the emissions of $\mathrm{CO}_{2}$, beginning from small scale interventions based on bioclimatic architecture. The conventional condominiums and blocks of the center could become more environmentally friendly with simple means, such as, green roofs or small scale water treatment plants that produce recycled water, roof top photovoltaic panels, planting trees and lightening surface colors.

As mentioned, there are notable buildings abandoned or underused. They are located in the city center, which is not extended and easy to walk in a short time. Combined with the numerous problems because of the mix of uses without spatial planning, the revival of those landmarks could be the key lever for socio-economical growth and the promotion of cultural heritage. Moreover, the management of similar uses (e.g. accommodation of some municipal services) in the same area and the connection with the local bus network could reduce the use of cars. 
It is widely known that sustainable development underlines the importance of social equality and embraces diversity. Komotini is a city with many contrasts, as there are many different regions within the city's limits that should be managed and developed equally by land use and spatial strategies that highlight each region's special features and smooth the differences between them. For instance, in one region the high-rise buildings next to low muslim houses, could be a strength, because it reduces the sense of being in a crowded space, and creates a characteristic skyline.

It is of great significance to create mix-use neighborhoods. Combined uses, such as residence, commerce, sports facilities, offices etc., should be found in every region of the city, in order to give them life during all day and prevent citizens from driving to center. Also, there are parcels of land that surround the city's infrastructure which are empty spaces. Policies that promote commercial and leisure activities in these areas are a tool for using all urban and suburban spaces in order to serve multiple uses and users. All the districts should be served by the public transportation.

Another major target is to develop an efficient public transport system and well-connected walkways to give city dwellers transport alternatives to driving. To promote sustainable transport in modern cities, particularly important is the use of human energy, also known as green or soft transportation [10]. It includes energy infrastructure, new technologies for reliable and accessible public transportation, and 'complete streets', with bike lanes, bioswales that infiltrate stormwater into the ground, trees to shade sidewalks to make for a more pleasant pedestrian experience [11]. All the above should be combined with measures, such as, access restrictions to city center, transfer stations on the suburbs (park\&ride), car pooling or car sharing, speed reduction especially in residential regions and of course, advertise these initiatives and inform people about their benefits.

As public concerns about the role of open-air spaces as a means of environmental improvement have escalated, the lack of common spaces is a major problem. Blending nature into the city, by adopting a strategy of pervasive greenery and transforming current parks and squares into aesthetical common spaces, softens the hard edges of a highly built up cityscape, reduces air pollution and reinforces socialization. Given the completion of the Urban Development Plan, new parks and playgrounds can be created inside the neighborhoods. Also, many of the existing ones could be redesigned, or local, recyclable materials could replace the conventional urban furniture.

It is important to promote measures aimed at upgrading the technical infrastructure. Monitoring infrastructure failures all over the municipality is a key step towards upgrading. For instance, during storms, many streets, like the west entrance to the city, close due to the increased water level, and this phenomenon is noted often all over the city. Such failures require immediate treatment.

Furthermore, the shift towards alternative and renewable energy, through community or european funds, is a fundamental for energy independence and conservation of the region's natural resources. The long in duration sunshine, the geothermal field of the area, the rich natural and water resources (Komotini combines mountainous areas with fertile plains and clean coastal areas), can be exploited towards sustainability, to increase energy autonomy of public spaces (e.g. installation of photovoltaic panels on lights or rain water recycling systems across the city).

Another indicative sector of the right function of a city is waste management. There is a properly designed and sufficiently managed landfill, as well as a mechanical biological treatment system near the city. However, the sanitation of deprived districts within the city is necessary. Additionally, there have been some primary attempts to promote recycling, and to update citizens about domestic and residential recycling.

\section{General conclusions}

Modern societies, especially in Mediterranean countries, are called to deal with the phenomenon of informal urban planning, because of lack of appropriate legislature, socio-economical institutions about urban and suburban space, political will, bureaucracy in land and spatial planning, and the general lack of consistent interrelationship between land management and land administration.

The urban structure and form of a city represent the cultural, environmental and economic priorities of its society [12]. As an organizational structure that manages the site, is required to long for balance between human needs and environmental protection. The design of space, the use of 
available resources, the waste or energy management, are fundamental issues that require renovation.

During the last decades and having such an important place in Northern Greece, the Municipality of Komotini grew rapidly. Its basic characteristics are high-density structures and the disparity between regions. Until the beginning of the last century, the city had no urban plan and kept growing without any spatial program. Since 1933, Komotini evolved according to a town plan following the existing oriental tracings, but eventually became insufficient for the new demands. In 2012 finally, the new general Urban Development Plan was approved, in order to ameliorate the city's form and expansions.

Within what is now an international framework of reflection on urban conservation, there is an ever-increasing awareness of these demands. All of this begs the question: will Komotini (or urban centers of Northern Greece in general), be able to respond to new developments taking place globally on sustainable development? The basic aim is to achieve a balanced, integrated, multisectoral spatial development strategy, which promotes a polycentric and balanced urban-regional system, green transportation and wise management of natural and cultural heritage, considering the environmental impact. Managing urban space is a complicated procedure that requires the collaboration of different specialists. The main aim is to make every effort to minimize the use of energy, water and materials at each stage of the city's life-cycle. And only when all the above factors will be reconciliated, modern cities will be capable of getting on track towards the sustainable city.

\section{References}

[1] C. Potsiou and C. Ioannidis: Informal Settlements in Greece: The Mystery of Missing Information and the Difficulty of Their Integration into a Legal Framework. In: Promoting Land Administration and Good Governance, 5th FIG Regional Conference, Ghana (March 811, 2006)

[2] Rodopi Prefecture, Recommendations of spatial planning (in Greek), Ministry of Urban Development, Housing and Environment, Athens (1984)

[3] Strategic Development Research Plan of Prefecture of Rodopi (in Greek), edited by RodopiEvros Super Prefecture, Rodopi Prefecture, Local Union of Municipalities and Communitites, Regional Development Agency of Rodopi, Research Committee DUTH, Komotini (2006)

[4] A. Aravantinos: Urban planning for a sustainable development of urban space (in Greek), University Studio Press, Athens (1997)

[5] B. Edgar, J. Taylor, Housing, in: P. Roberts, H. Sykes: Urban Regeneration: a Handbook, SAGE Publications Ltd, London (2000), pp. 153-175

[6] G. Voulgaris, A. Voulgarakis, G. Zaglis, X. Kolovos, G. Selinas, D. Kalivas: Depiction and comparative analysis of the spatial distribution of urban green in 11 Greek cities (in Greek), Agricultural Univ. Athens, Dep. Agricultural Economics\&Rural Development, Athens (2010)

[7] Bioclimatic Design\&Urban Regeneration for Sustainable Development, edited by Dimitra Babalis, Edizioni Polistampa, Firenze (2003)

[8] C. Kennedy, S. Pincetl, P. Bunje: The study of urban metabolism and its applications to urban planning and design, Environmental Pollution, 159 (2011), pp. 1965-1973

[9] P. Newman: Sustainability and cities: extending the metabolism model, Landscape and Urban Planning 44 (1999), pp. 219-226 
[10] E. Andrikopoulou, A. Giannakou, G. Kafkalas, M. Pitsiava-Latinopoulou: City and urban policies for the urban sustainable development (in Greek), Kritiki, Thessaloniki (2007)

[11] S. Pincetl: Urban Metabolism and the Nature of Sustainable Cities, interview to Jon Christensen, The Huffington Post (2013). Information on http://www.huffingtonpost.com/green

[12] E. Andreadaki: Bioclimatic planning. Environment and sustainability (in Greek), University Studio Press, Thessaloniki (2006) 